\title{
LEAF VARIATION AMONG CANNABIS SPECIES FROM A CONTROLLED GARDEN
}

\author{
LORAN C. ANDERSON ${ }^{1}$
}

The genus Cannabis has had a long association with man and contains considerable variation in growth form, achene size, and chemical content. The variation has taxonomically been variously interpreted. Some maintain the genus is polytypic with at least three species (Emboden, 1974; Schultes et al., 1974). Others (Small and Cronquist, 1976) believe that it is properly viewed as monotypic: i.e. limited to $C$. sativa $\mathrm{L}$. They do, however, recognize several infraspecific varieties.

Historical aspects and rationale for the different treatments are amply covered in these papers.

My work on wood anatomy (Anderson, 1974) supported the polytypic generic concept. A controlled garden $(2.6$ acres) is maintained at the University of Mississippi by the School of Pharmacy for the National Institute on Drug Abuse where collections from throughout the world are propagated. In 1976, I visited the facility several times to obtain additional vouchered wood samples from plants grown in a uniform garden. While gathering the Cannabis samples, I became aware of differences in leaf morphology. Variation in garden-grown plants has already been noted by Quimby et al. (1973), but they did not quantify their data. This report analyzes leaf form in Cannabis and compares the variation in relation to the alternative taxonomic treatments.

\section{METHODS AND MATERIALS}

Measurements were made from the largest leaf on each voucher specimen. Dimensional data were taken from the central (longest) leaflet. Measurements as illustrated in Fig. 1 included leaflet

\footnotetext{
'Department of Biological Science, Florida State University, Tallahassee, Florida and Associate in Economic Plant Morphology in the Botanical Museum, Harvard University.
} 
length (L), leaflet width and length to the widest point. Ratios of width to length ( W/L) and length to widest point to total length (WP/L) were determined. Leaflet number, plant height and sex of the sample were also recorded.

Statistical analyses were made with assistance from Dr. David Schrader; these analyses of all materials are on file at Florida State University. Ken Womble and Melanie Darst helped with graphics.

A total of 377 samples were measured. Most materials came from the Mississippi garden. The University of Mississippi School of Pharmacy and Dr. C. E. Turner are thanked for making their facilities and the plants available. Some garden plantings were maintained for several generations: therefore, samples were taken only from original seed sources to prevent possibility of garden hybridizations. I collected sixty specimens representing thirty-nine different seed sources. That somewhat extensive population sample was augmented by the intensive sampling from the garden in 1972 by Dr. R. E. Schultes and his colleagues (with 237 specimens from thirty-two seed sources). Vouchers are preseved at the Florida State University and the Botanical Museum of Harvard University, respectively. An additional eighty specimens from different wild or naturalized populations were studied at the Gray Herbarium and Arnold Arboretum.

\section{RESULTS}

Samples were placed in four categories based mainly on growth form. The three major forms are illustrated in Fig. 2. Those classed as C. sativa were taken from tall, laxly branched plants (S, in the tables). Relatively tall plants with very narrow leaflets and small achenes were classed as C. sativa, small-seeded (SS); short, compact plants that were densely branched were classed as $C$. indica Lam. (I); and those mature plants that were two feet tall or less and unbranched, as $C$. ruderalis Janisch. (R).

Mean data for leaf morphology for the four categories and three collection sets are given in Table 1. The four categories in my 1976 sampling were all significantly different for $\mathrm{W} / \mathrm{L}$ and 
$\mathrm{WP} / \mathrm{L}$ at the $99.9 \%$ level of confidence, as determined by a Student's $t$-test. Statistical analyses were not made on the other sets, due partly to absence of garden material of $C$. ruderalis in 1972.

Garden plants maintained their relative growth patterns: i.e., height and branching; but leaves were noticeably larger under cultivation (compare 1976 and 1972 versus "wild" in Table 1). Although leaves were larger, dimensional ratios of the central leaflet $(\mathrm{W} / \mathrm{L}$ and $\mathrm{WP} / \mathrm{L})$ did not vary significantly between garden-grown and wild samples.

Massed data for all three collection groupings are given for the four categories in Table 2. None of these categories is significantly distinct for leaflet length, although $C$. ruderalis consistantly has small leaves. The small-seeded, narrow leaved $C$. sativa $(\mathrm{SS})$ from India and Pakistan is not so significantly distinct from C. sativa (S) as is C. indica. No formal infraspecific status is proposed for those small-seeded plants, but further study is warranted.

The three species, C. sativa, $C$. indica, and C.ruderalis, are well defined in leaflet width/length ratios, and the latter two are also distinguished from $C$. sativa in their oblanceolate leaflets (WP/L). Leaf morphology groupings reported here are compatible for those of the holotypes of $C$. sativa and $C$. indica; the type specimen of $C$. ruderalis was not available for measurement.

Modal leaflet number for $C$. sativa was 7 with a mean of 6.35 . Leaves of $C$. indica had a mode of 9 (mean, 8.20), and C. ruderalis had a modal leaflet number of 5 (mean, 4.59). No significant differences were found in leaf morphology between sexes of a given species, but in a few populations the female plants had wider leaflets than did the males.

Leaf character sets were generally reinforcing: i.e., leaves of $C$. indica that were unusually narrow and thereby somewhat like those of $C$. sativa were also very oblanceolate. The most nearly intermediate leaf morphology was found in a stout Japanese cultivar of $C$. sativa with $\mathrm{W} / \mathrm{L}=.143$ and $\mathrm{WP} / \mathrm{L}=.524$. It was unique in having smooth stalks (few if any trichomes) and no THC content. Multivariate analysis would have dramatized the distinctness of the foliar characteristics of the species more completely, but $t$-tests were considered ample. 
Table 1. Mean measurements for leaf morphology in Cannabis. ${ }^{*}$

\begin{tabular}{lcccc} 
& $\begin{array}{c}\text { Collection } \\
\text { set }\end{array}$ & $\mathrm{L}(\mathrm{mm})$ & $\mathrm{Leaf}$ Features \\
\hline C. sativa $(\mathrm{S})$ & 1976 & 131.7 & .133 & .460 \\
& 1972 & 128.5 & .108 & .420 \\
& wild & 114.2 & .110 & .423 \\
C. sativa (SS) & 1976 & 93.0 & .101 & .505 \\
& 1972 & 90.9 & .094 & .422 \\
& wild & 65.4 & .097 & .402 \\
C. ruderalis $(\mathrm{R})$ & 1976 & 67.1 & .163 & .536 \\
& 1972 & - & -214 & .517 \\
C. indica $(\mathrm{I})$ & wild & 59.5 & .214 & .578 \\
& 1976 & 143.3 & .207 & .560 \\
& 1972 & 118.3 & .172 & .579 \\
\hline
\end{tabular}

*See text and Fig. 1 for key to leaf features; $C$. ruderalis was not grown in the garden in 1972.

Table 2. Combined set mean data* for leaf morphology in Cannabis

\begin{tabular}{|c|c|c|c|c|}
\hline Leaf Feature & C. sativa (S) & C. sativa (SS) & C. ruderalis (R) & C. indica (I) \\
\hline $\mathrm{L}$ & 125.9 & 78.8 & 61.8 & 117.0 \\
\hline $\mathrm{W} / \mathrm{L}$ & .105 & .094 & .203 & .182 \\
\hline $\mathrm{WP} / \mathrm{L}$ & .436 & .426 & .523 & .565 \\
\hline
\end{tabular}

* Means connected with $=$ are not significantly different $(\mathrm{p}=>.1)$ Means connected with __are significantly different at $\mathrm{p}=.1-.05$

Means not connected are very significantly different at $\mathrm{p}=<.01$ 


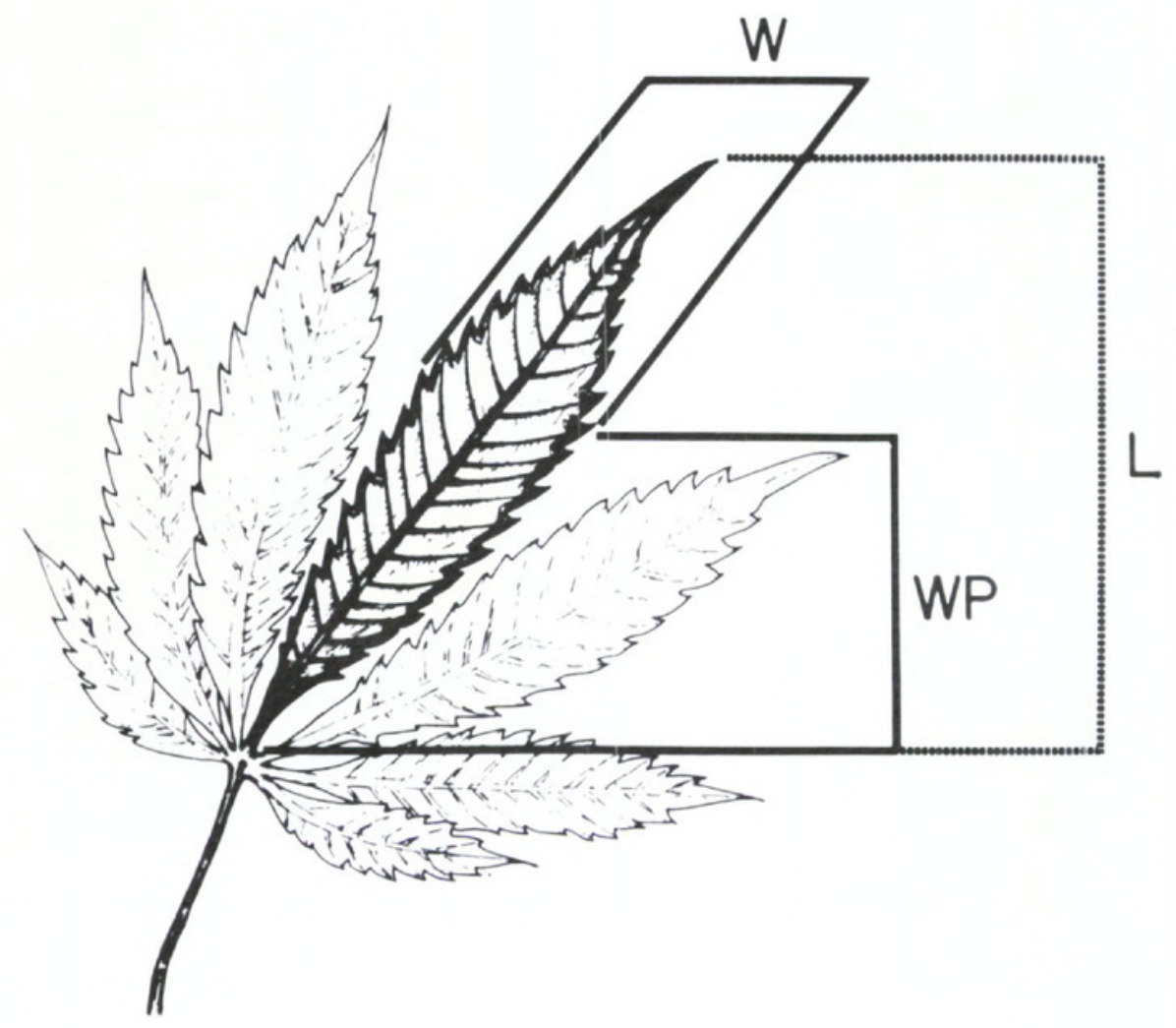

Fig. 1. Tracing of leaf of $C$. indica from plant grown in garden from seed from Afghanistan (Anderson 4390; garden accession AF-G), showing measurements made on central leaflet. $\mathrm{L}=$ leaflet length, $\mathrm{W}=$ width, and $\mathrm{WP}=$ length to widest point of leaflet. The ratios of $\mathrm{W} / \mathrm{L}$ and $\mathrm{WP} / \mathrm{L}$ for the various sets of plants are given in Tables 1 and 2 . 

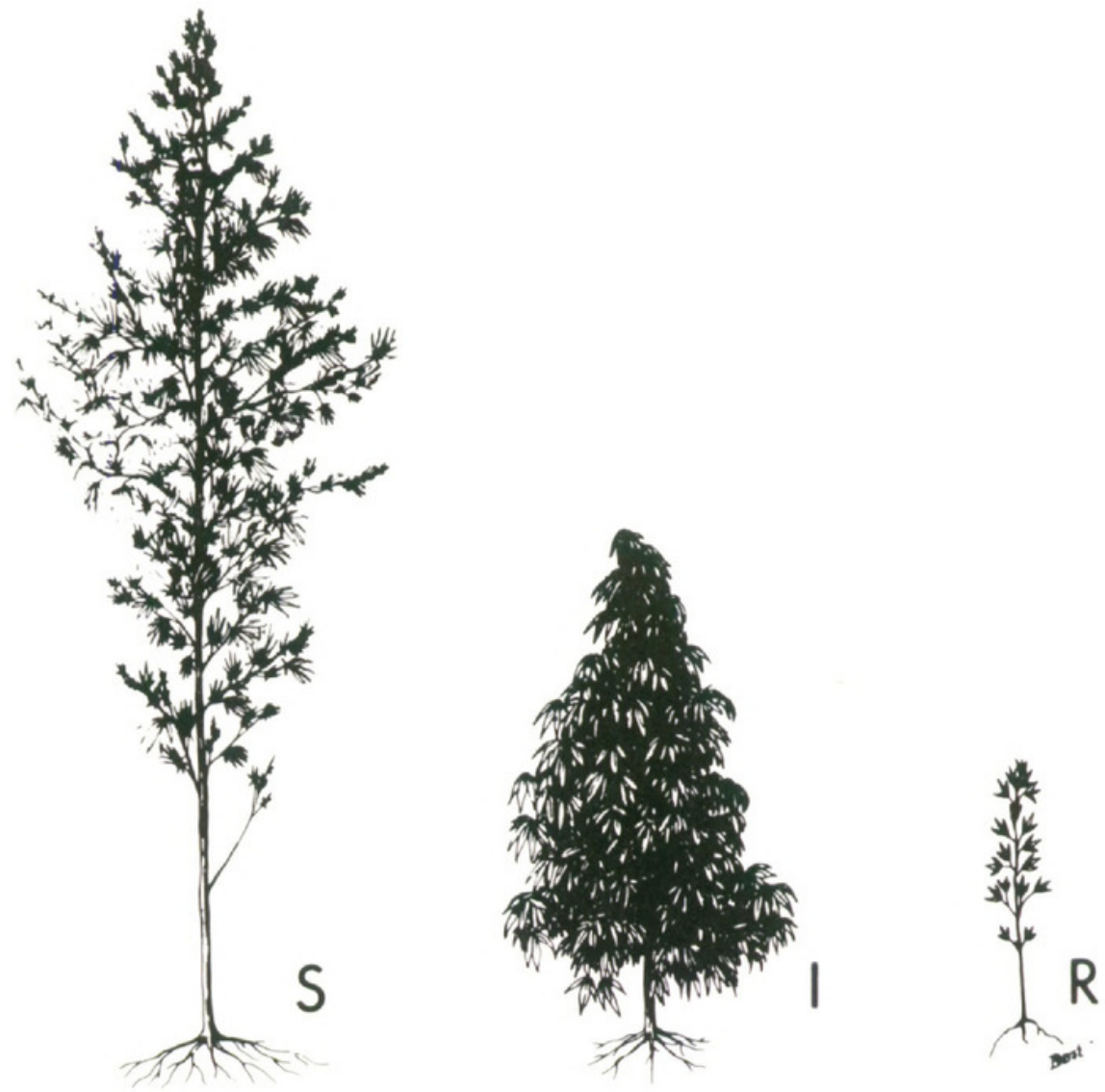

Fig. 2. Growth patterns in Cannabis species; $\mathrm{S}=C$. sativa, $\mathrm{I}=C$. indica, and $\mathrm{R}=C$. ruderalis. Plants drawn with representative heights of eight, four, and two feet, respectively. 


\section{DISCUSSION}

Differing views on the taxonomy of Cannabis have generated much interest - perhaps more so in forensic circles than in scientific settings. Still, species delimitations should be determined on the plant biology rather than on legal implications or societal needs (c.f., Small, 1975).

Leaflet morphology and number do correlate well with the distinctive growth forms of the species (Fig. 2). Three major groupings of features are found, and each represents a named species. They are as follows:

1. Cannabis sativa: Plants relatively tall, 5-18 feet tall or more, laxly branched; leaves usually palmately compound with (3) 5-7 (11) leaflets, central leaflet lanceolate with $\mathrm{W} / \mathrm{L}$ ratio (.05) .09-.12 (.15). Environmentally induced unifoliate (simple) leaves of garden plants from Thailand were also narrowly lanceolate.

2. Cannabis indica: Plants short, 2-4 feet tall, pyramidal, compactly branched; leaflets (5) 7-11 (13), central leaflet oblanceolate with $\mathrm{W} / \mathrm{L}$ ratios (.14) .17-.21 (.35).

3. Cannabis ruderalis: Plants (female) very short, $0.5-2$ feet tall, usually unbranched; leaflets 3-5 (7), central leaflet elliptic with $\mathrm{W} / \mathrm{L}$ ratio (.10) .16-.21 (.45).

Plant heights given are those under normal conditions; $C$. sativa can be photo-induced to flower in the seedling stage. These three complements of characteristics are found in wild or weedy settings and are maintained in the uniform garden. None of the features appear to be simply environmental variants.

Features of wood anatomy also distinguished $C$. sativa and $C$. indica (Anderson, 1974). Study of the woods of garden samples is nearly complete. The additional samples are corroborative for those two species, and C. ruderalis wood is intermediate to that of the other two species but distinctive.

Other features such as plant odor, leaf color and leaflet serration pattern may prove to be of taxonomic value, but they were not quantified in this study. Similarly, seed (achene) features may be helpful, but I did not collect seeds. Earlier taxonomic 
applications of achene data are contradictory (Emboden, 1974; Small and Cronquist, 1976).

Recent proponents of the monotypic view of Cannabis (Small and Conquist, 1976) emphasize chemical data and interfertility of the plants. Data from hybridization experiments are sometimes over-emphasized. Those which can be achieved through artificial hybridization in the garden or greenhouse often give an exaggerated view of biological interactions among natural populations. In general, interspecific hybridization is a relatively frequent phenomenon (Knoblock, 1959), especially so in windpollinated species such as Cannabis. The ability to hybridize or not is not recommended as a sole or major species criterion, because the degree of fertility among interspecific hybrids varies widely (Stace, 1975). This is particularly true for many weedy plants (like Cannabis); Baker (1972) states: "A full spectrum of interspecific hybridization can be seen in the world's weed flora, from the formation of sterile $F_{1}$ hybrids to the production of vigorous, fertile amphidiploids or significant introgression."

Species of Cannabis are not mutually exclusive in their cannabinoid content, and cannabinoids are known to fluctuate in quantity and composition during the life cycle of the plant. Consequently, a study group sponsored by the United Nations Narcotics Laboratory (1976) stated that "cannabinoid composition can serve only as a limited chemotaxonomic tool." Turner $e t$ al. (1973) demonstrated that cannabinoid composition is not stable in stored plant material, and Turner (pers. comm.) has noted daily fluctuations in cannabinoid content in living plants. Therefore, a single plant might be classified with Small and Cronquist's key (1976) as C. sativa ssp. sativa at one time of day and as C. sativa ssp. indica at another time of day! Clearly the use of chemical data as primary taxonomic criteria (Small and Cronquist, 1976) is neither practical nor natural and has been duly criticized by Emboden (1977).

Judging from Small's annotations on herbarium sheets, his predilection to classify plants by intoxicant ability and/or geographical distribution has resulted in placing many plants of C. sativa in with $C$. indica. Consequently, the two groups would then not represent distinctive morphological forms (perhaps this contributed to his recognition of the groups as subspecies rather 
than species). My circumscription of $C$. indica is narrower than that which constitutes $C$. sativa ssp. indica (Lam.) Small \& Cronquist. Thus, it should be noted that studies based on material supplied by Small (such as Clark and Bohm, 1979) would reflect his wider interpretation of $C$. indica as a subspecies of $C$. sativa.

The genus Cannabis might best be described on morphology rather than chemical composition as having three closely related but distinct species: C. sativa, $C$. indica, and $C$. ruderalis. One species, C. sativa, itself is extremely variable, having been domesticated by early man for use as food, fibre, oil, medicine, and hallucinogen.

\section{LITERATURE CITED}

Anderson, L. C. 1974. A study of systematic wood anatomy in Cannabis. Harvard Univ. Bot. Mus. Leafl. 24: 29-36.

Baker, H. G. 1972. Migration of weeds, In Taxonomy, Phytogeography, and Evolution (D. H. Valentine, ed.), Academic Press, New York.

Clark, M. N. and B. A. Bohm. 1979. Flavonoid variation in Cannabis L. Bot. J. Linn. Soc. 79: 249-257.

Emboden, W. A. 1974. Cannabis - a polytypic genus. Econ. Bot. 28: 304-310.

Emboden, W. A. 1977. A taxonomy of Cannabis. Taxon 26: 110.

Knoblock, I. W. 1959. A preliminary estimate of the importance of hybridization in speciation. Bull. Torr. Bot. Club 86: 296-299.

Quimby, M. W., N. J. Doorenbos, C. E. Turner, and A. Masoud. 1973. Mississippi-grown marihuana-Cannabis sativa. Cultivation and observed morphological variations. Econ. Bot. 27: 117-127.

Schultes, R. E., W. M. Klein, T. Plowman, and T. E. Lockwood. 1974. Cannabis: an example of taxonomic neglect. Harvard Univ. Bot. Mus. Leafl. 23: 337-367.

Small, E. 1975. On toadstool soup and legal species of Cannabis. Pl. Sci. Bull. 21: 34-39.

Small, E. and A. Cronquist. 1976. A practical and natural taxonomy for Cannabis. Taxon 25: 405-435.

Stace, C. A. 1975. Hybridization and the Flora of the British Isles. Academic Press, New York.

Turner, C. E., K. W. Hadley, P. S. Fetterman, N. J. Doorenbos, M. W. Quimby, and C. Walter. 1973. Constituents of Cannabis sativa L. IV: Stability of cannabinoids in stored plant material. J. Pharm. Sci. 62: 1601-1605.

United Nations. 1976. The botany and chemotaxonomy of Cannabis. United Nations document MNAR/15/1976, Geneva. 


\section{$2 \mathrm{BHL}$ Biodiversity Heritage Library}

Anderson, Loran C. 1980. "Leaf Variation among Cannabis Species from a Controlled Garden." Botanical Museum leaflets, Harvard University 28(1), 61-69. https://doi.org/10.5962/p.168641.

View This Item Online: $\underline{\text { https://www.biodiversitylibrary.org/item/31875 }}$

DOI: https://doi.org/10.5962/p.168641

Permalink: https://www.biodiversitylibrary.org/partpdf/168641

\section{Holding Institution}

Missouri Botanical Garden, Peter H. Raven Library

\section{Sponsored by}

Missouri Botanical Garden

\section{Copyright \& Reuse}

Copyright Status: Public domain. The BHL considers that this work is no longer under copyright protection.

This document was created from content at the Biodiversity Heritage Library, the world's largest open access digital library for biodiversity literature and archives. Visit BHL at https://www.biodiversitylibrary.org. 